\title{
Synthesis and characterization of carbon dots from coconut shell by optimizing the hydrothermal carbonization process
}

\section{K. Abinaya}

Department of Nano Science and Technology, Tamil Nadu Agricultural University, Coimbatore - 641003 (Tamil Nadu), India

\section{S.K. Rajkishore*}

Department of Nano Science and Technology, Tamil Nadu Agricultural University, Coimbatore - 641003 (Tamil Nadu), India

\section{A. Lakshmanan}

Department of Nano Science and Technology, Tamil Nadu Agricultural University, Coimbatore - 641003 (Tamil Nadu), India

\section{R. Anandham}

Department of Agricultural Microbiology, Tamil Nadu Agricultural University, Coimbatore - 641003 (Tamil Nadu), India

\section{P. Dhananchezhiyan}

Department of Farm Machinery and Power Engineering, Tamil Nadu Agricultural University, Coimbatore - 641003 (Tamil Nadu), India

\section{Praghadeesh}

Department of Nano Science and Technology, Tamil Nadu Agricultural University, Coimbatore - 641003 (Tamil Nadu), India

${ }^{*}$ Corresponding author. Email: rajkishoresk@gmail.com

\section{How to Cite}

Abinaya, K. et al. (2021). Synthesis and characterization of carbon dots from coconut shell by optimizing the hydrothermal carbonization process. Journal of Applied and Natural Science, 13(4), 1151 - 1157. https://doi.org/10.31018/jans.v13i4.2916

\begin{abstract}
Coconut shell is one of the major agro-by products vis-a-vis agro-waste generated by coconut processing units. At present, Coconut shells are largely utilized as feed material for thermal power conversion by various allied industrial sectors, which is a highly energy inefficient and ecologically unfriendly process. The present study aimed to generate activated carbon dots/ carbon nanomaterials with a wide range of potential applications through a relatively less energy dependant hydrothermal carbonization process. Hydrothermal carbonization is a one-step, simple, low cost and environmental friendly approach to obtain carbon dots. The findings demonstrate that coconut shells when subjected to hydrothermal carbonization process at $250^{\circ} \mathrm{C}$ for $6 \mathrm{~h}$ produced uniform-sized, stable, negatively charged and amorphous forms of carbon dots. Characterization of carbon dots using High-Resolution Transmission Electron Microscopy (HR-TEM), Scanning Electron Microscopy (SEM), Selected Area Electron Diffraction (SAED), X- ray Diffractometer (XRD), UV- Visible Spectroscopy, Particle Size Analyzer (PSA), Brunauer-EmmettTeller (BET) Analyzer, Elemental Dispersive X-ray (EDX) analyzer and Fourier Transform Infrared Spectroscopy (FTIR) had conclusively confirmed the versatility of the carbon dots generation process and were able to achieve stable $2 \mathrm{~nm}-\mathrm{sized}$, spherical shaped carbon dots with numerous downstream applications. The study will help the conversion of agro-waste coconut shells into useful bio-based fluorescent carbon dots.
\end{abstract}

Keywords: Coconut shell, Hydrochar, Hydrothermal carbonization, Carbon dots

\section{INTRODUCTION}

Carbon dots ( $\mathrm{C}$ dots) are the youngest member of the nanomaterial family with quasi-zero dimension and size regime of less than $10 \mathrm{~nm}$. These novel carbon nanomaterials have attracted much attention due to their good optical stability, excellent water solubility, low tox- icity, biocompatibility, easy surface modification and functionalization (Zhi et al., 2018; Dias et al., 2019). These unique characteristics allow the carbon dots to be extensively used in biosensing, in-vitro and in-vivo bioimaging, photocatalytic sensing, solar energy harvesting, food safety, drug-gene delivery system, explosive detection and environmental remediation and 
monitoring. Hydrothermal carbonization is a thermochemical and bottom up process that converts raw biomass into value-added products in the temperature regime of $150-350{ }^{\circ} \mathrm{C}$ which is much lower than pyrolysis $\left(450-550^{\circ} \mathrm{C}\right)$ and gasification $\left(900-1200{ }^{\circ} \mathrm{C}\right)$ temperature (Liu et al., 2010). Thus, the hydrothermal carbonization process has a great scope for synthesizing carbon dots from a wide range of biomasses (Sharma et al., 2019). Carbon dots have been prepared with different biomass precursors like lemon juice (Gharat et al., 2019), Bee pollens (Zhang et al., 2015), coffee grounds (Crista et al., 2020), cocoon silk (Wu et al., 2013), papaya (Kasibabu et al., 2015), peach gum (Lin et al., 2019), crab shell (Yao et al., 2017), cow manure (Horst et al., 2021), sugarcane juice (Mehta et al., 2014), red cabbage (Sharma et al., 2020), tea waste (Chen et al., 2019), water chestnut and onion (Hu et al., 2017), Eutrophic algal blooms (Ramanan et al., 2016), Lactobacillus plantarum (Lin et al., 2017) and orange juice (Sahu et al., 2012). Although few studies have attempted to explore the possibilities of deriving $C$ dot from coconut shell, this present study focused on optimising the parameters to obtain a stable and higher yield of $\mathrm{C}$ dots.

Coconut shell is an agricultural residue that accounts for around $85 \%$ of the weight of the fruit (Ayrilmis et al., 2011 ) and has an average composition of $33.30 \%$ lignin, $30.58 \%$ cellulose, $26.70 \%$, hemicellulose, $8.86 \%$ water and $0.56 \%$ ash (Arena et al., 2016). Since cellulose and hemicellulose material are requisites for the synthesis of carbon dots, according to the "one-stonetwo-birds" strategy, hydrothermal carbonization process is a green, economic, one-pot method for synthesizing C-dots. With this background the present study aimed to synthesize biomass-derived carbon dots from coconut shells using a hydrothermal reactor by optimizing parameters besides characterizing to understand the morphology, functional group, stability, surface charge and optical properties.

\section{MATERIALS AND METHODS}

Coconut shells were collected from the coconut residue processing unit located at Pollachi in Tamil Nadu, India. The coconut shells free from coconut coir were washed, air dried and ground to a fine powder using impact pulveriser and sieved under British Standard Sieve (BSS) 200 (75 micron mesh) to obtain the uniform-sized particles and stored in airtight plastic bags until use. Distilled water was used throughout the experiments. A hydrothermal reactor capacity of $120 \mathrm{ml}$ was used for the synthesis of carbon dots.

\section{Synthesis of carbon dots}

Carbon dots were prepared by hydrothermal treatment of powdered coconut shells. In a typical synthesis, $3 \mathrm{~g}$ of the powdered sample was added into $75 \mathrm{ml}$ of distilled water in the ratio of $1: 25$. The mixture was then transferred into a $120 \mathrm{ml}$ steel-lined reactor and heated at $250{ }^{\circ} \mathrm{C}$ for $6 \mathrm{~h}$. The Carbon dots were collected by removing larger particles through centrifugation at $10,000 \mathrm{rpm}$ for $20 \mathrm{~min}$. Then it was filtered using 0.22 $\mu \mathrm{m}$ syringe filter to remove larger micron particles and the pale yellow solution was dried under a hot air oven for $48 \mathrm{~h}$ and re-dispersed in distilled water at a concentration of $1 \mathrm{mg} / \mathrm{ml}$ for further characterization.

\section{Scanning Electron Microscopy (SEM)}

The morphology of the sample was analyzed by using Scanning Electron Microscope (FEI, Quanta 250). For analysis, $1 \mathrm{mg}$ of sample was dispersed in $10 \mathrm{ml}$ of distilled water to prepare a suspension solution. A drop of the suspension was mounted on the carbon tape using a micropipette and allowed to air dry before imaging at 20000X magnification.

\section{Energy Dispersive X-Ray Spectroscopy (EDAX)}

The chemical composition of a sample was recorded on Energy Dispersive X-Ray Spectroscopy in conjunction with Scanning Electron Microscopy. The beam of electron with energy $10-20 \mathrm{keV}$ was allowed to strike the conducting sample surface causing $X$ - rays to emit from the material and emitted $X$ - rays depend on the sample material under examination (Titus et al., 2019).

\section{High Resolution -Transmission Electron Micro- scope (HR-TEM)}

The sizes of the carbon dots were measured under High-Resolution Transmission Electron Microscopy with $200 \mathrm{kV}$. The particle sizes were statistically measured using image $\mathrm{J}$ software. For analysis, $1 \mathrm{mg}$ of sample was dispersed in $1 \mathrm{ml}$ of distilled water and dropped on to the copper grid using a micropipette. Then, it was allowed to air dry and placed in sample holder for imaging by following the protocol outlined in (Chunduri et al., 2017).

\section{Selected Area Electron Diffraction (SAED)}

The crystal structure of the material was determined by SAED which is performed inside Transmission Electron Microscope. When the beam of the electron was passed through a sample, its crystal lattice acted as a diffraction grating and the electrons were scattered and resulted in a diffraction pattern (Zhou and Thomson, 2009). The obtained diffraction pattern was confirmed with XRD result.

\section{Zeta potential}

The zeta potential measurement is related to the surface charge of a solid phase in contact with the liquid medium. 
The measures of dispersion stability were measured using the Nano -Particle Size Analyzer (Model: HORIBA-SZ-100), in which the zeta potential was measured between $-200 \mathrm{mV}$ to $+200 \mathrm{mV}$.

\section{Brunauer-Emmett-Teller (BET) analyzer}

Prior to assessment of surface area, pore size and pore volume of carbon dots, carbon dots were subjected to degassing procedure for 3 hours at $200^{\circ} \mathrm{C}$ in order to remove undesirable vapors and gases in the samples. Once the degassing was completed, the sample cell was transferred to the analysis port. The interaction between the sample surface and adsorbent (Nitrogen) occurs at the sample analysis port and the surface area, pore size and pore volume of the samples were measured and documented using BET Quantachrome TouchWin ${ }^{\mathrm{TM}}$ version 1.22

\section{Fourier Transform Infrared Spectroscopy (FTIR)}

The functional group as well as chemical bonding of carbon dots, was recorded by Fourier- Transform Infrared (FTIR) using Jasco Model: R- 3000-QE. A pinch of the sample was placed on the sample port and Infrared radiation of about $10,000-100 \mathrm{~cm}^{-1}$ is passed through the sample and part of the radiation is absorbed and some pass through the sample. The sample converts the absorbed radiation to vibrational or rotational energy. The detector detects the resultant signal generally from 4000 to $400 \mathrm{~cm}^{-1}$ which is the molecular fingerprint of the sample. The data obtained were plotted using ORIGIN Ver.8.5.

\section{X- Ray Diffraction (XRD)}

The nature of the powder materials was recorded on a powder X-Ray Diffractometer (XRD) Using Shimadzu,

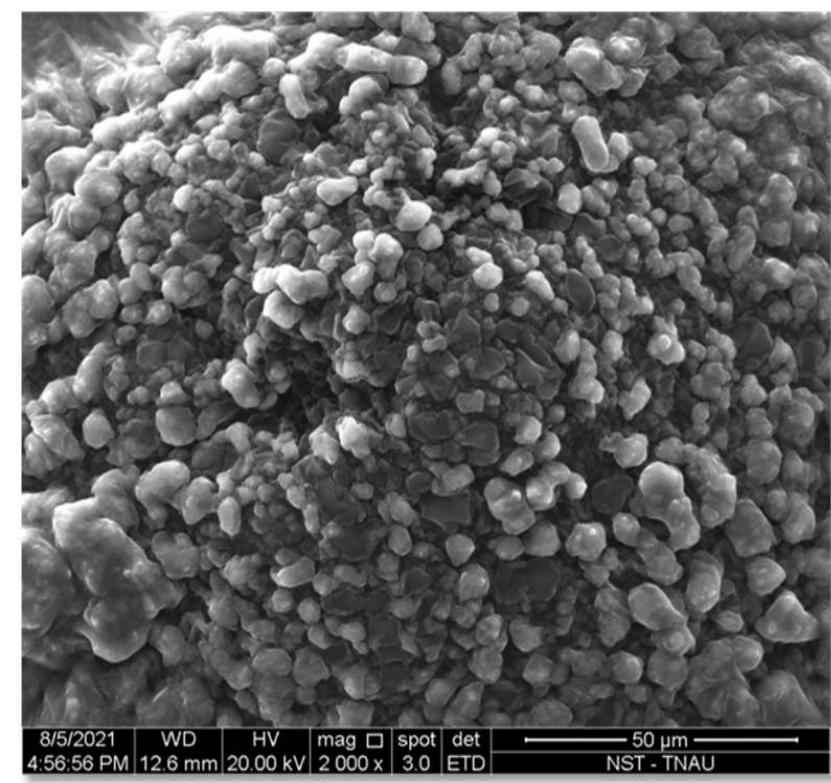

Fig.1 A. SEM image showing the carbonization of carbon dots
Model: XRD 600 using $\mathrm{Cu}$ Ka radiation $(\lambda=1.54 \AA)$, monochromator, $40 \mathrm{Kv}$ current with scan speed of $10000 \mathrm{deg} / \mathrm{min}$ and scan range between 1,00,000$9,00,000$ degree Which is rapid and non-destructive analytical technique. The powder samples were placed on the sample holders and then subjected for analysis and data obtained were plotted using ORIGIN Ver.8.5.

\section{UV- Visible Spectroscopy}

The optical properties were determined by UV-Vis absorption spectrum using Specord 210 plus. The sample was filled in a quartz cuvette and used for absorption measurements in the UV range transparent to the wavelengths above $190 \mathrm{~nm}$. The wavelength of the sample is determined by the sample's maximum absorption level (Skoog et al., 2017). The data obtained were plotted using ORIGIN Ver.8.5.

\section{RESULTS AND DISCUSSION}

\section{Size distribution and morphology}

In this study, the reaction time of the carbonization process was optimized for 6 hour duration as it produced stable carbon dots within the size less than $10 \mathrm{~nm}$ compared to $2 \mathrm{~h}$ and $4 \mathrm{~h}$ reaction time. The carbon dots obtained via hydrothermal carbonization of coconut shell powder at $250^{\circ} \mathrm{C}$ for $6 \mathrm{~h}$ followed by centrifugation and filtration were subjected to characterization. The SEM image of the carbon dots showed the particles are spherical, uniform in distribution (Fig.1 A and Fig 1 B). These morphological results are in line with the observations of Kang et al. (2020), who reported the synthesis of carbon dots from graphite rods through the electrolysis method and found that the carbon dot particles were spherical and uniform in distribution. In addi-

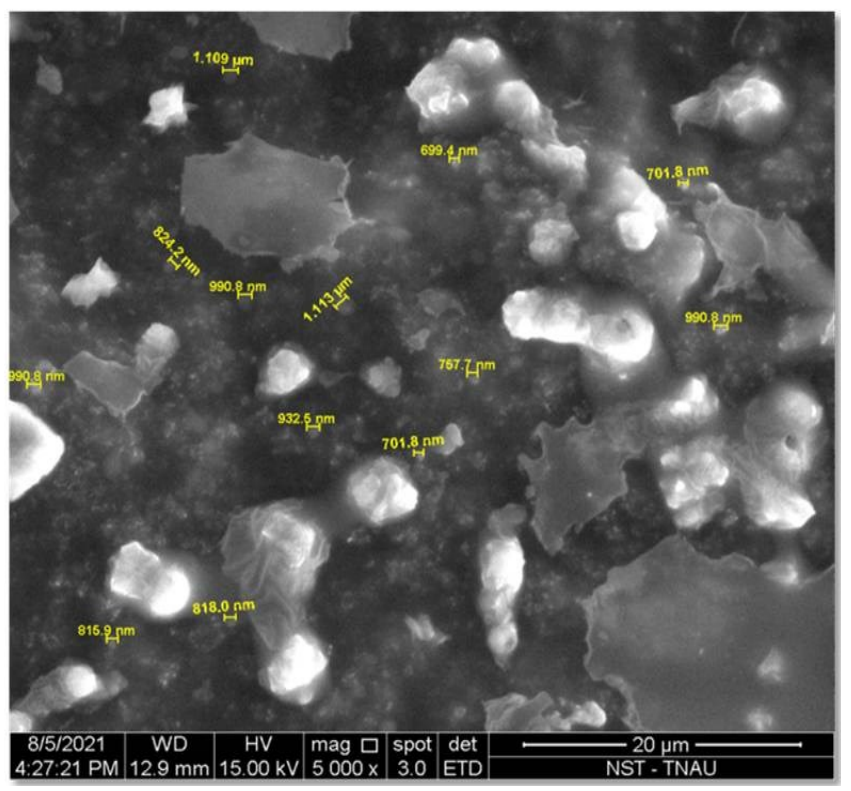

Fig.1 B. SEM image showing the carbon particles at 20 $\mu m$ resolution 


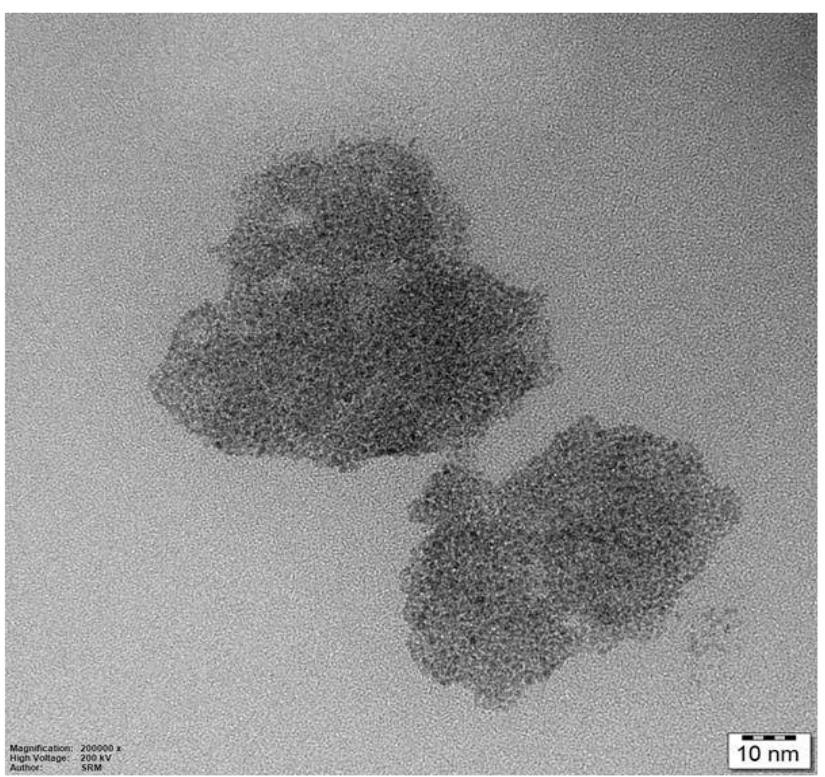

Fig. 2 A. HR-TEM image showing the carbon dots at 10 $n m$ resolution

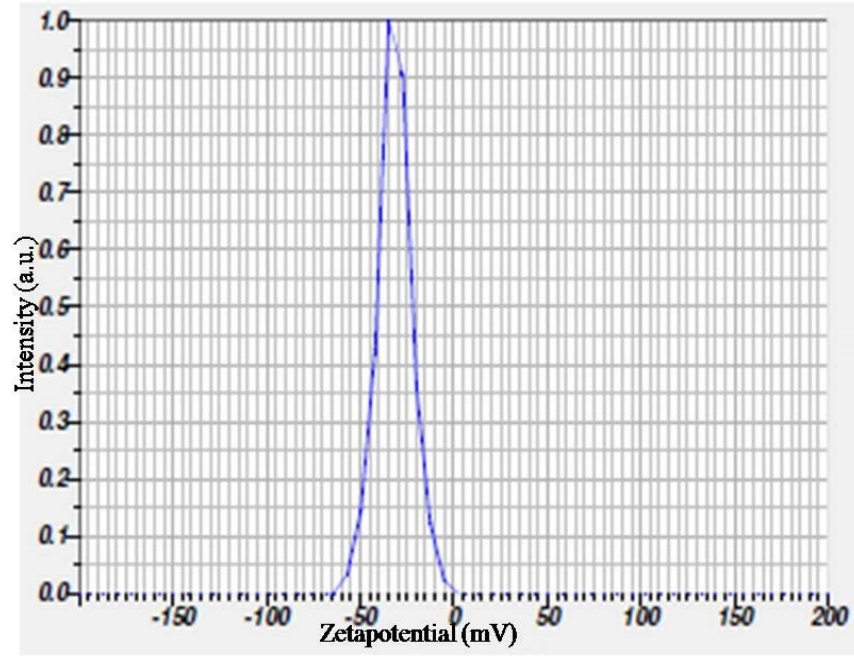

Fig. 3. Zeta potential graph showing the stability of carbon dots at $-32 \mathrm{mV}$

tion, Kang et al. (2020) reported that XRD pattern analysis of carbon dots synthesized by electrolysis method exhibited strong agglomeration effect, which is a potential deterrent in the application point of view of carbon dots and highly limits its usability. In contrast, the carbon dot synthesized by the hydrothermal carbonization in the current study was relatively stable and did not exhibit agglomeration effect. The HR-TEM image showed that the synthesized Carbon dots from coconut shell were spherical and monodisperse with narrow size distribution around 2nm (Fig. 2 A and Fig. 2 B) and results are consistent with the reports of Yuan et al. (2015), who reported that the hydrothermal synthesis of carbon dots from wheat straw and found that synthesized carbon dots were less than $2 \mathrm{~nm}$. The zeta potential of carbon dots synthesized at $250^{\circ} \mathrm{C}$ for $2 \mathrm{~h}, 4 \mathrm{~h}$ showed less than $-20 \mathrm{mV}$, confirming that the particles

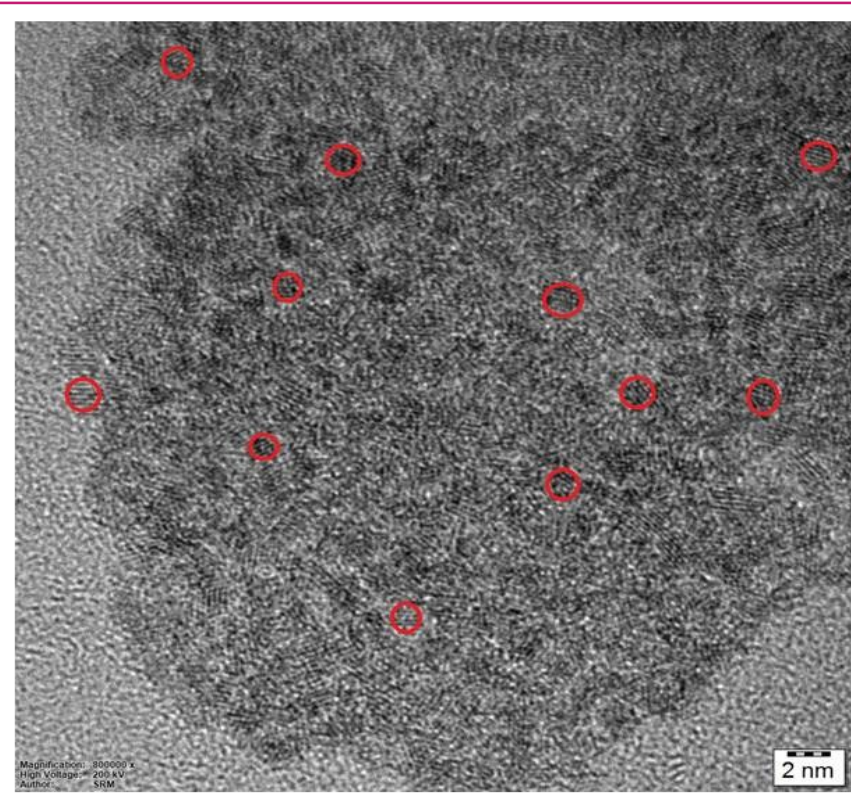

Fig.2 B. HR-TEM image showing the carbon dots at $2 \mathrm{~nm}$ resolution

were no longer stable, whereas carbon dots synthesized at $250^{\circ} \mathrm{C}$ for $6 \mathrm{~h}$ recorded $-32 \mathrm{mV}$ indicated that these are stable in nature (Fig. 3). The negative sign indicated the charge might be due to various carboxyl, carbonyl and hydroxyl groups present on the surface of the carbon dots. These observations coincide with our FT-IR results. The wavelength of the carbon dots showed the absorbance at $280 \mathrm{~nm}$ attributed with the $\mathrm{n}$ $-\pi^{*}$ transition of the $\mathrm{C}=\mathrm{O}$ band $\pi-\Pi^{*}$ transitions of the $\mathrm{C}=\mathrm{C}$ band and the formation of carbon dots were confirmed by pale yellow solution in day light and bright blue emission under UV illumination as $(365 \mathrm{~nm})$ shown in Fig. 4. These UV-Vis results are consistent with the observations of Nguyen et al. (2020), who reported the hydrothermal synthesis of carbon dots from banana peels and found that the carbon dots exhibited the absorbance peak at $280 \mathrm{~nm}$ which is attributed with the $n-\pi^{*}$

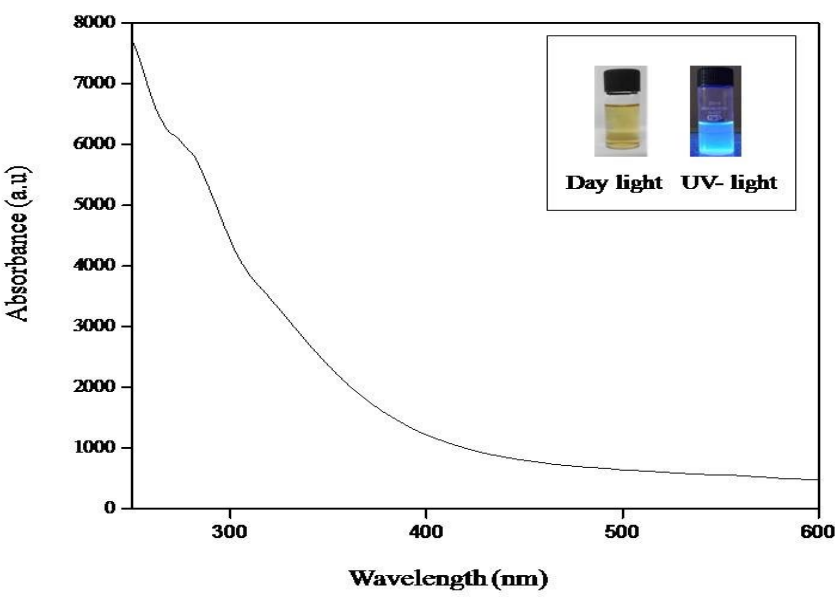

Fig. 4. UV-Vis spectrum of carbon dots showing the absorption peak at $280 \mathrm{~nm}$. Inset: Photograph of the obtained Carbon dots solution under irradiation of day light (left) and $365 \mathrm{~nm}$ UV light (right) 


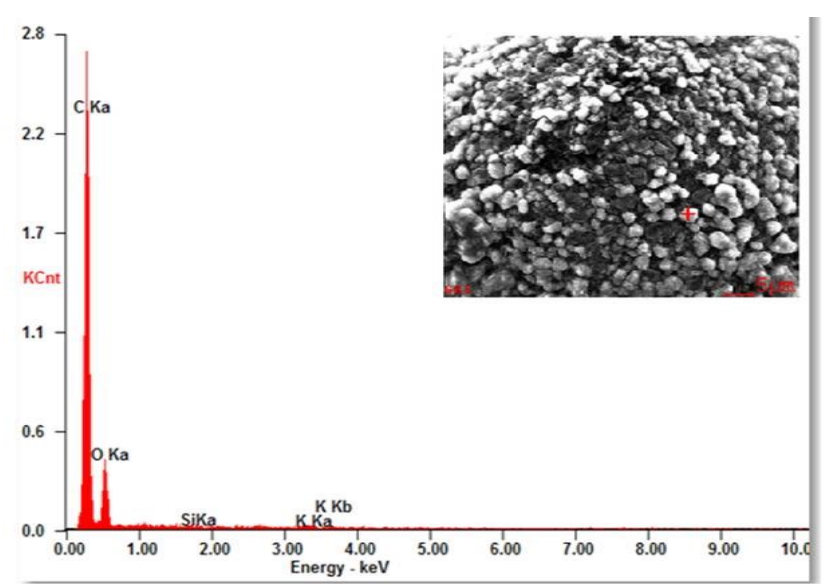

Fig. 5. EDAX graph showing the elemental composition of carbon dots

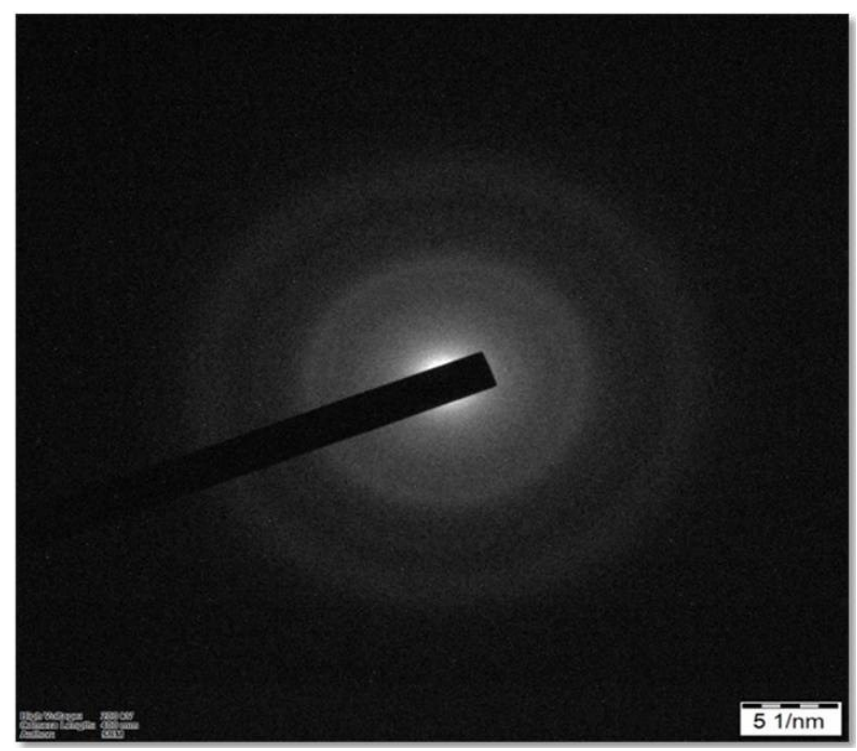

Fig. 7. SAED pattern confirming the amorphous nature of carbon dots

transition of the $\mathrm{C}=\mathrm{O}$ band $\pi-\pi^{*}$ transitions of the $\mathrm{C}=\mathrm{C}$ band. Further, they implored the dual advantage of the generation of carbon dots and activated carbon.

\section{Chemical nature of the carbon dots}

The highest peak in EDAX showed the presence of carbon, oxygen followed by silicon and potassium with $75.42,24.18,00.11,00.29$ weight percentages as presented in Fig. 5.and Table 1. The XRD spectrum (Fig. 6) confirmed that the synthesized carbon dots were amorphous in nature. The Selected Area Electron Diffraction (SAED) pattern of carbon dots showed diffuse rings (Fig. 7) and it was consistent with the above XRD data. Such results corroborate with the findings of Shaikh et al. (2019), who reported that the hydrothermal synthesis of carbon dots from Citrus limetta and showed that the carbon dot particles were amorphous in nature. The FTIR spectra at a strong peak $3435 \mathrm{~cm}^{-1}$ showed symmetrical and asymmetrical stretching

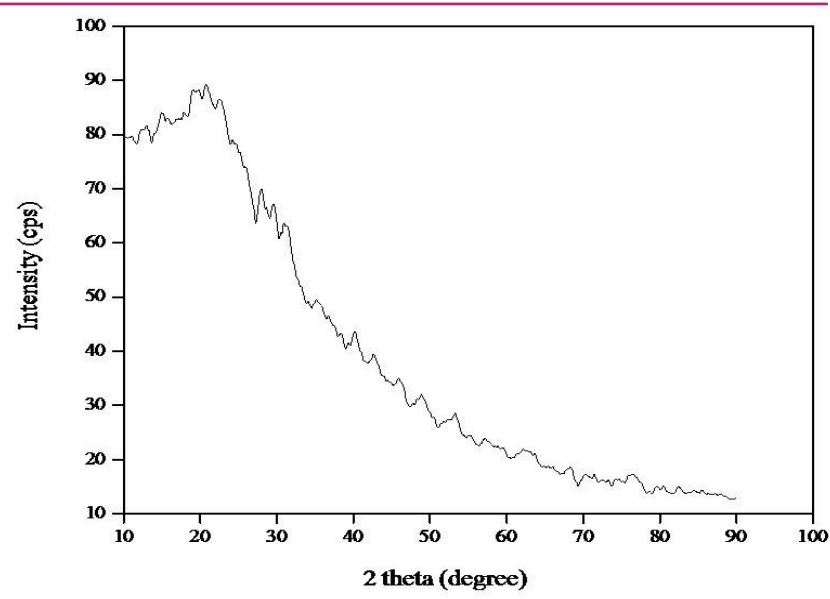

Fig.6. $X R D$ spectra showing the amorphous nature of carbon dots

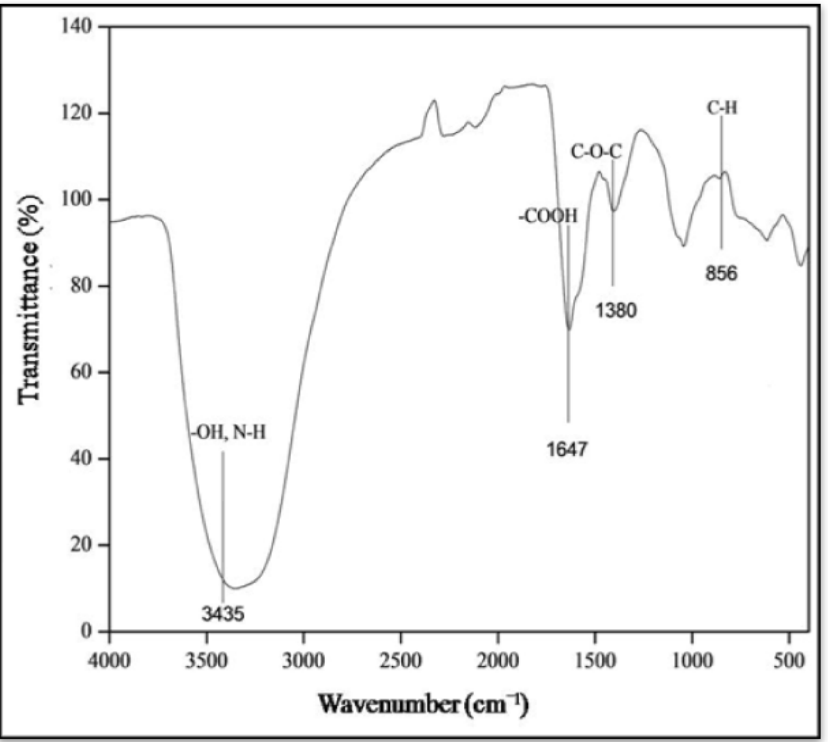

Fig. 8. FTIR spectra showing the chemical bonds of carbon dots

of $-\mathrm{OH}$ and $\mathrm{N}-\mathrm{H}$. The peak at $1647 \mathrm{~cm}^{-1}$ corresponds to the functional group $-\mathrm{COOH}$. The peak at $1380 \mathrm{~cm}-1$ indicates $\mathrm{C}-\mathrm{O}-\mathrm{C}$ asymmetric stretch or $\mathrm{C}-\mathrm{H}$ bending arising from a methyl functional group. The aromatic plane $\mathrm{C}-\mathrm{H}$ bending corresponding to peak around 900 $669 \mathrm{~cm}^{-1}$ is shown in the Fig. 8. The FTIR datasets generated in the current study are in line with the dataset of Shaikh et.al. (2019), who reported a similar FTIR spectra profile of strong peak at $3435 \mathrm{~cm}^{-1}$, symmetrical and asymmetrical stretching pattern of functional groups in carbon dots synthesized from Citrus limetta by hydrothermal method. BET results showed that the surface area of carbon dots produced from the shell was $25.483 \mathrm{~m}^{2} / \mathrm{g}$. The total pore volume of carbon dots was found to be $0.0085119 \mathrm{cc} / \mathrm{g}$ and the average pore diameter was found to be $0.66805 \mathrm{~nm}$. Here the pore diameter represented the intervoid spaces between the carbon dots and the absolute isotherm result showed that the carbon dots were nonporous material (Cejka 
Abinaya, K. et al. / J. Appl. \& Nat. Sci. 13(4), 1151 - 1157 (2021)

Table 1. Elemental composition of carbon dots calculated via EDAX

\begin{tabular}{lll}
\hline Element & Wt $\%$ & At $\%$ \\
\hline CK & 75.42 & 80.48 \\
OK & 24.18 & 19.37 \\
SiK & 00.11 & 00.05 \\
KK & 00.29 & 00.09 \\
\hline
\end{tabular}

and Mintova, 2007). Overall, in the hydrothermal carbonization reaction, the hydronium ions are generated, leading to the hydrolysis of carbohydrates. Sucrose undergoes hydrolysis to form glucose and fructose and the starch forms maltose, glucose and fructose (Funke and Ziegler, 2010). The glucose and fructose decompose to form organic acids, which catalyze the hydrolysis of maltose to monosaccharide that undergo dehydration and fragmentation (ring opens and $\mathrm{C}-\mathrm{C}$ bond breaks), which results in the soluble products. They undergo intermolecular dehydration and aldol condensation leading to polymerization. These polymers undergo aromatization to form $\mathrm{C}=\mathrm{O}$ groups (Jain et al. 2016) and lead to the formation of activated carbon and carbon dots. Interestingly, these reactions primarily depend upon the feed and go in a parallel manner rather than the consecutive reaction. Thus, hydrothermal carbonization method is widely recognized as sustainable, cost-effective, environmental friendly and facile technology for the synthesis of carbon dots.

\section{Conclusion}

Numerous research initiatives have gained importance to develop low-cost, high volume, stable carbon dots from waste materials. The hydrothermal approach is by far a relatively energy-efficient process that yields stable carbon dots within the expected size range of $<10$ $\mathrm{nm}$. Further, findings from our study conclusively proved that coconut shell powder could serve as an excellent precursor for synthesising stable carbon dots. In addition, the process of carbon dots synthesis using coconut shells by hydrothermal carbonization also resulted in the generation of a facile, costless and environmental-friendly hydrochar, an important and widely used adsorbent for pollution remediation. XRD results in the current study revealed that synthesized carbon dots were amorphous and in good agreement with the SAED pattern. The carbon dots exhibited blue fluorescence, soluble in water and were found to have an average size of $2 \mathrm{~nm}$. Besides, the zeta potential measurements showed that these novel carbon nanomaterials were stable with abundant hydroxyl group on its surface that made them amenable for functionalization and repurposing them for specific applications catering the needs of industries. Overall, this investigation confirms that hydrothermal carbonization is an effective and simple chemical process to transform coconut waste biomass into a valuable resource, namely carbon dots.

\section{ACKNOWLEDGEMENTS}

This dataset is the outcome of the external project funded by the Coconut Development Board (CDB), Kochi and the authors are thankful to the CDB and the Department of Nano Science and Technology, Tamil Nadu Agricultural University, Coimbatore, India for all the support.

\section{Conflict of interest}

The authors declare that they have no conflict of interest.

\section{REFERENCES}

1. Chunduri, L. A. A., Kurdekar, A., Patnaik, S., Aditha, S., Prathibha, C. \& Kamisetti, V. (2017). Single step synthesis of carbon quantum dots from coconut shell: evaluation for antioxidant efficacy and hemotoxicity. J. Mater. Sci. Appl., 3(6), 83-93. https://doi.org/10.1166/mat.2016.1289

2. Arena, N., Lee, J. \& Clift, R. (2016). Life Cycle Assessment of activated carbon production from coconut shells. Journal of Cleaner Production, 125, 68-77. https:// doi.org/10.1016/j.jclepro.2016.03.073

3. Ayrilmis, N., Jarusombuti, S., Fueangvivat, V., Bauchongkol, P. \& White, R. H. (2011). Coir fiber reinforced polypropylene composite panel for automotive interior applications. Fibers and polymers, 12(7), 919-926. https:// doi.org/10.1007/s12221-011-0919-1

4. Cejka, J. \& Mintova, S. (2007). Perspectives of micro/ mesoporous composites in catalysis. Catalysis Reviews, 49(4), 457-509.

5. Chen, K., Qing, W., Hu, W., Lu, M., Wang, Y. \& Liu, X. (2019). On-off-on fluorescent carbon dots from waste tea: Their properties, antioxidant and selective detection of $\mathrm{CrO}_{4}{ }^{2}-, \mathrm{Fe}^{3+}$, ascorbic acid and L-cysteine in real samples. Spectrochimica acta Part A: Molecular and Biomolecular Spectroscopy, 213, 228-234. DOI: 10.1016/ j.saa.2019.01.066

6. Crista, D., El Mragui, A., Algarra, M., Esteves da Silva, J. C., Luque, R. \& Pinto da Silva, L. (2020). Turning spent coffee grounds into sustainable precursors for the fabrication of carbon dots. Nanomaterials, 10(6), 1209. DOI: 10.3390/nano10061209

7. Dias, C., Vasimalai, N., P Sárria, M., Pinheiro, I., VilasBoas, V., Peixoto, J. \& Espiña, B. (2019). Biocompatibility 
and bioimaging potential of fruit-based carbon dots. Nanomaterials, 9(2), 199. DOI: 10.3390/nano90 20 199

8. Funke, A. \& Ziegler, F. (2010). Hydrothermal carbonization of biomass: a summary and discussion of chemical mechanisms for process engineering. Biofuels, Bioproducts and Biorefining, 4(2), 160-177. https://doi.org/1 $0.1002 / \mathrm{bbb} .198$

9. Gharat, P. M., Pal, H. \& Choudhury, S. D. (2019). Photophysics and luminescence quenching of carbon dots derived from lemon juice and glycerol. Spectrochimica acta Part A: Molecular and Biomolecular Spectroscopy, 209, 14-21. DOI: 10.1016/j.saa.2018.10.029

10. Horst, F. H., da Silva Rodrigues, C. V., Carvalho, P. H. P. R., Leite, A. M., Azevedo, R. B., Neto, B. A. \& Rodrigues, M. O. (2021). From cow manure to bioactive carbon dots: a light-up probe for bioimaging investigations, glucose detection and potential immunotherapy agent for melanoma skin cancer. RSC Advances, 11(11), 6346-6352. https://doi.org/10.1039/D0RA10859F

11. Hu, Y., Zhang, L., Li, X., Liu, R., Lin, L. \& Zhao, S. (2017). Green preparation of $S$ and N Co-doped carbon dots from water chestnut and onion as well as their use as an off-on fluorescent probe for the quantification and imaging of coenzyme A. ACS Sustainable Chemistry \& Engineering, 5(6), 4992-5000. https://doi.org/10.1021/acssuschem eng. $7 \mathrm{~b} 00393$

12. Jain, A., Balasubramanian, R. \& Srinivasan, M. P. (2016). Hydrothermal conversion of biomass waste to activated carbon with high porosity: A review. Chemical Engineering Journal, 283, 789-805. https://doi.org/10.1016/j.cej.2015.0 8.014

13. Kang, X., Wu, L., Xu, J., Liu, D., Song, Q. \& Hu, Y. (2020, July). Preparation and photoelectrochemical properties of porous silicon/carbon dots composites. In IOP Conference Series: Materials Science and Engineering (Vol. 892, No. 1, p. 012025). IOP Publishing.

14. Kasibabu, B. S. B., D'souza, S. L., Jha, S. \& Kailasa, S. K. (2015). Imaging of bacterial and fungal cells using fluorescent carbon dots prepared from carica papaya juice. Journal of fluorescence, 25(4), 803-810. DOI: 10.1007/s10895-015-1595-0

15. Lin, F., Li, C., Dong, L., Fu, D. \& Chen, Z. (2017). Imaging biofilm-encased microorganisms using carbon dots derived from L. plantarum. Nanoscale, 9(26), 9056-9064.

16. Lin, Y., Chen, Z., Yu, C. \& Zhong, W. (2019). Heteroatomdoped sheet-like and hierarchical porous carbon based on natural biomass small molecule peach gum for highperformance supercapacitors. ACS Sustainable Chemistry \& Engineering, 7(3), 3389-3403.

17. Liu, Z., Zhang, F. S. \& Wu, J. 2010). Characterization and application of chars produced from pinewood pyrolysis and hydrothermal treatment. Fuel, 89(2), 510-514.

18. Mehta, V. N., Jha, S. \& Kailasa, S. K. (2014). One-pot green synthesis of carbon dots by using Saccharum officinarum juice for fluorescent imaging of bacteria (Escherichia coli) and yeast (Saccharomyces cerevisiae) cells. Materials Science and Engineering: C, 38, 20-27.

19. Nguyen, T. N., Le, P. A. \& Phung, V. B. T. (2020). Facile green synthesis of carbon quantum dots and biomass- derived activated carbon from banana peels: synthesis and investigation. Biomass Conversion and Biorefinery, 1-10.

20. Ramanan, V., Thiyagarajan, S. K., Raji, K., Suresh, R., Sekar, R. \& Ramamurthy, P. (2016). Outright green synthesis of fluorescent carbon dots from eutrophic algal blooms for in vitro imaging. ACS Sustainable Chemistry \& Engineering, 4(9), 4724-4731.

21. Sahu, S., Behera, B., Maiti, T. K. \& Mohapatra, S. (2012). Simple one-step synthesis of highly luminescent carbon dots from orange juice: application as excellent bioimaging agents. Chemical Communications, 48(70), 88358837.

22. Shaikh, A. F., Tamboli, M. S., Patil, R. H., Bhan, A., Ambekar, J. D. \& Kale, B. B. (2019). Bioinspired carbon quantum dots: an antibiofilm agents. Journal of Nanoscience and Nanotechnology, 19(4), 2339-2345.

23. Sharma, N., Das, G. S. \& Yun, K. (2020). Green synthesis of multipurpose carbon quantum dots from red cabbage and estimation of their antioxidant potential and biolabeling activity. Applied Microbiology and Biotechnology, 104(16), 7187-7200

24. Sharma, V., Singh, S. K. \& Mobin, S. M. (2019). Bioinspired carbon dots: from rose petals to tunable emissive nanodots. Nanoscale Advances, 1(4), 1290-1296.

25. Skoog, D. A., Holler, F. J., \& Crouch, S. R. (2017). Principles of instrumental analysis. Cengage learning.

26. Titus, D., Samuel, E. J. J. \& Roopan, S. M. (2019). Nanoparticle characterization techniques In Green synthesis, characterization and applications of nanoparticles, Elsevier, (pp. 303-319).

27. Wu, Z. L., Zhang, P., Gao, M. X., Liu, C. F., Wang, W., Leng, F. \& Huang, C. Z. (2013). One-pot hydrothermal synthesis of highly luminescent nitrogen-doped amphoteric carbon dots for bioimaging from Bombyx mori silknatural proteins. Journal of Materials Chemistry $B, 1(22)$, 2868-2873.

28. Yao, Y. Y., Gedda, G., Girma, W. M., Yen, C. L., Ling, Y. C. \& Chang, J. Y. (2017). Magnetofluorescent carbon dots derived from crab shell for targeted dual-modality bioimaging and drug delivery. ACS applied materials \& interfaces, 9(16), 13887-13899.

29. Yuan, M., Zhong, R., Gao, H., Li, W., Yun, X., Liu, J. \& Zhang, F. (2015). One-step, green, and economic synthesis of water-soluble photoluminescent carbon dots by hydrothermal treatment of wheat straw, and their bioapplications in labeling, imaging, and sensing. Applied Surface Science, 355, 1136-1144.

30. Zhang, J., Yuan, Y., Liang, G. \& Yu, S. H. (2015). Scale $\square$ up synthesis of fragrant nitrogen $\square$ doped carbon dots from bee pollens for bioimaging and catalysis. Advanced Science, 2(4), 1500002

31. Zhi, B., Gallagher, M. J., Frank, B. P., Lyons, T. Y., Qiu, T. A., Da, J. \& Haynes, C. L. (2018). Investigation of phosphorous doping effects on polymeric carbon dots: fluorescence, photostability, and environmental impact. Car bon, 129, 438-449.

32. Zhou, X. \& Thompson, G. E. (2009). Electron and Photon Based Spatially Resolved Techniques In Shreir's Corrosion. Elsevier BV. 